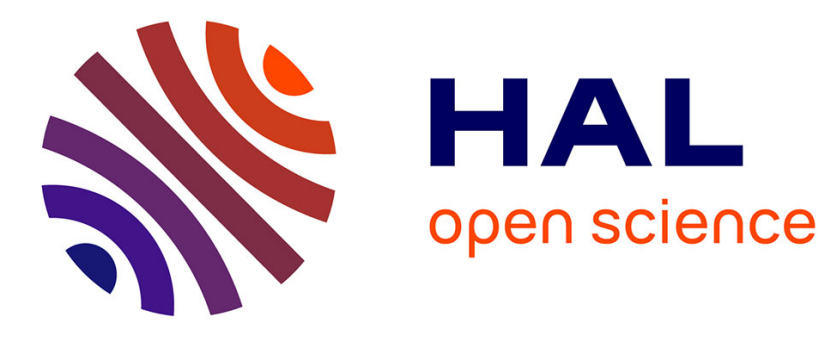

\title{
Thermal annealing of amorphous Ti-Si-O thin films
} Abbas Hodroj, Odette Chaix-Pluchery, Marc Audier, Ulrich Gottlieb, Jean-Luc Deschanvres

\section{To cite this version:}

Abbas Hodroj, Odette Chaix-Pluchery, Marc Audier, Ulrich Gottlieb, Jean-Luc Deschanvres. Thermal annealing of amorphous Ti-Si-O thin films. Journal of Materials Research, 2008, 23 (3), pp.755. 10.1557/JMR.2008.0088 . hal-00261588

\section{HAL Id: hal-00261588 \\ https://hal.science/hal-00261588}

Submitted on 7 Mar 2008

HAL is a multi-disciplinary open access archive for the deposit and dissemination of scientific research documents, whether they are published or not. The documents may come from teaching and research institutions in France or abroad, or from public or private research centers.
L'archive ouverte pluridisciplinaire HAL, est destinée au dépôt et à la diffusion de documents scientifiques de niveau recherche, publiés ou non, émanant des établissements d'enseignement et de recherche français ou étrangers, des laboratoires publics ou privés. 


\title{
Thermal annealing of amorphous Ti-Si-O thin films
}

\author{
Abbas Hodroj ${ }^{*}$, Odette Chaix-Pluchery, Marc Audier, Ulrich Gottlieb \\ and Jean-Luc Deschanvres
}

Laboratoire des Matériaux et du Génie Physique, CNRS, INP Grenobl e-Minatec, 3 parvis Louis Néel, BP 257, 38016 Grenoble Cedex 1, France

\begin{abstract}
Ti-Si-O thin films were deposited using an aerosol chemical vapor deposition process at atmospheric pressure. The film structure and microstructure were analysed using several techniques before and after thermal annealing. Diffraction results indicate that the films remain X-ray amorphous after annealing whereas Fourier transform infrared spectroscopy gives evidence of a phase segregation between amorphous $\mathrm{SiO}_{2}$ and well crystallized anatase $\mathrm{TiO}_{2}$. Crystallization of anatase $\mathrm{TiO}_{2}$ is also clearly shown in the Raman spectra. Transmission electron microscopy analysis indicates that anatase $\mathrm{TiO}_{2}$ nanograins are embedded in a $\mathrm{SiO}_{2}$ matrix in an alternated $\mathrm{SiO}_{2} / \mathrm{TiO}_{2}$ multilayer structure.
\end{abstract}

Keywords: Ti-Si-O thin films, Aerosol CVD, Multilayered microstructure, Mictamict.

*Corresponding author, E-mail: Abbas.Hodroj@inpg.fr 


\section{INTRODUCTION}

Mixed titania-silica $\left(\mathrm{TiO}_{2}-\mathrm{SiO}_{2}\right)$ amorphous films cover a wide range of achievable refractive index because of the large difference of the refractive index of the two compounds. This property is useful for the preparation of several optical devices (antireflective coatings ${ }^{1}$, passive ${ }^{2}$ or active ${ }^{3}$ waveguides, notch filter ${ }^{4}$ ). The mixed $\mathrm{TiO}_{2}-\mathrm{SiO}_{2}$ thin films can also be used as dielectric materials due to a high dielectric constant, a high breakdown field and a low leakage current. ${ }^{5}$ These films have been deposited by various physical methods such as electron beam evaporation $^{6}$, sputtering ${ }^{5,7}$, pulsed laser deposition ${ }^{8}$ and chemical methods such as sol gel ${ }^{9-11}$ and chemical vapour deposition (CVD) with low-pressure systems ${ }^{12,13}$ or with assisted process (ultraviolet $(\mathrm{UV})^{14}$ or plasma $^{15}$ ). In a previous paper, we reported a new process to obtain Ti-Si-O films by an aerosol CVD process at atmospheric pressure ${ }^{16}$. The as-deposited films are amorphous and the relative proportions of $\mathrm{TiO}_{2}$ and $\mathrm{SiO}_{2}$ are controlled in function of the deposition conditions.

As previously mentioned, mixed Ti-Si-O thin films have a larger number of applications in the amorphous state. These films are also obtained as composite materials with crystallized titania embedded in silica matrix. Machida et al. ${ }^{17}$ reported that the addition of $\mathrm{SiO}_{2}$ into a $\mathrm{TiO}_{2}$ film yields optimum photoinduced superhydrophilicity. Such films with crystallized $\mathrm{TiO}_{2}$ grains can be also obtained from amorphous Ti-Si-O films by thermal annealing.

Since $\mathrm{TiO}_{2}$ and $\mathrm{SiO}_{2}$ are immiscible ${ }^{18}$, any crystallization in the mixed films implies segregation or exodiffusion of Ti. The segregation phenomenon is well reported by Sankur et al. ${ }^{6}$ : in codeposited $\mathrm{TiO}_{2}-\mathrm{SiO}_{2}$ films, $\mathrm{TiO}_{2}$ crystallizes in anatase structure between 600 and $900^{\circ} \mathrm{C}$ and in rutile phase between 900 and $1100^{\circ} \mathrm{C}$. The crystallization temperature as well as the crystal size depend on the initial composition of the film. The segregation mechanism is controlled by the Ti diffusion in the film.

In this paper we study the influence of thermal annealing under different gas atmospheres on the structure and microstructure of mixed $\mathrm{TiO}_{2}-\mathrm{SiO}_{2}$ films deposited by aerosol CVD.

\section{EXPERIMENTAL}

The Ti-Si-O thin films of about $100 \mathrm{~nm}$ thickness were deposited on $\mathrm{Si}$ (100) substrate using an atmospheric aerosol CVD reactor. A precursor solution was transformed in an aerosol by ultrasonic spraying and, after transport, it was deposited by pyrolysis on a heated substrate ${ }^{19}$. Titanium tetrabutoxide and di-acetoxi di-butoxisilane were used as precursors, butanol-1 as solvent and acetic acid and acetylacetone as adducts. More details on this experimental process 
are reported in Refs. 16 and 20. Thermal transformations of two types of films were studied: films deposited at $550^{\circ} \mathrm{C}$ with a $\mathrm{TiO}_{2} / \mathrm{SiO}_{2}$ atomic ratio of $40 / 60(\mathrm{~A})$ with a density of $2.56 \mathrm{~g} / \mathrm{cm}^{3}$ and films deposited at $500^{\circ} \mathrm{C}$ with a $\mathrm{TiO}_{2} / \mathrm{SiO}_{2}$ atomic ratio of $56 / 44$ (B) with a density of 2.61 $\mathrm{g} / \mathrm{cm}^{3}$. The film composition and density were obtained from X-ray Photoelectron Spectroscopy (XPS) and electron probe microanalysis. Pure $\mathrm{TiO}_{2}$ and $\mathrm{SiO}_{2}$ reference films were grown using the same process.

Annealing treatments were performed at different temperatures ranging from $700^{\circ} \mathrm{C}$ to $950^{\circ} \mathrm{C}$ for 1 to 12 hours in air or argon atmosphere.

X-ray diffraction (XRD) data were obtained on a $\theta / 2 \theta$ Siemens D500 (Bruker-AXS, Marne la Vallée, France) powder diffractometer $\left(\mathrm{Cu} K_{\alpha 1} \lambda=0.15406 \mathrm{~nm}\right)$ or on a Siemens D500 (BrukerAXS) powder diffractometer $\left(\mathrm{Fe} K_{\alpha 1} \lambda=0.19374 \mathrm{~nm}\right)$ at grazing incidence angle of $3^{\circ}$. Fourier transform infrared spectroscopy (FTIR) measurements were performed in transmission geometry using a "BioRad" spectrometer. Raman spectra were collected using a Jobin Yvon/Horiba LabRam spectrometer (Villeneuve d'Asq, France) equipped with a liquid nitrogen cooled chargecoupled device (CCD) detector. Experiments were conducted in the micro-Raman mode at room temperature in a backscattering geometry. The $514.5 \mathrm{~nm}$ line of an $\mathrm{Ar}^{+}$laser was focused to a spot size smaller than $1 \mu \mathrm{m}$. The incidence laser power measured at the sample surface was close to $7 \mathrm{~mW}$. Cross sections of Ti-Si-O thin film specimens were characterized by Transmission Electron Microscopy (TEM) using a high resolution JEOL 2010 (Tokyo, Japan). Observations were made on small fragments, obtained by scraping the thin film surfaces, deposited on copper grids coated with a carbon film.

\section{RESULTS AND DISCUSSION}

XRD diagrams of both types of films (atomic ratio $\mathrm{TiO}_{2} / \mathrm{SiO}_{2}=40 / 60$ and 56/44) obtained either in a classical $\theta / 2 \theta$ configuration or with grazing incidence showed no Bragg reflections. Either an amorphous or a nanocrystalline state below the X-ray coherence length can explain such diagrams.

FTIR absorption spectra of amorphous $\mathrm{SiO}_{2}$, anatase $\mathrm{TiO}_{2}$ and mixed A films before and after annealing for 1 hour at $950^{\circ} \mathrm{C}$ under air are shown in Fig. 1. The pure $\mathrm{SiO}_{2}$ spectrum (Fig. 1a) presents absorption bands at 450 and $1075 \mathrm{~cm}^{-1}$ attributed to Si-O-Si asymmetric rocking and stretching vibrations, respectively ${ }^{5}$. Absorption bands observed at 435 and $260 \mathrm{~cm}^{-1}$ in the case of pure $\mathrm{TiO}_{2}$ (Fig. 1b) are characteristic of the $\mathrm{TiO}_{2}$ anatase crystal structure ${ }^{21,22}$. For the asdeposited A film spectrum (Fig. 1c), the broad absorption band at around $440 \mathrm{~cm}^{-1}$ may result 
from a mixture of both Si-O-Si and Ti-O bands; the bands at 930 and $1050 \mathrm{~cm}^{-1}$ come from Ti-O$\mathrm{Si}$ and Si-O-Si bonding, respectively ${ }^{5}$. After annealing (Fig. 1d), the Si-O-Si band is slightly shifted to $\sim 1060 \mathrm{~cm}^{-1}$ and its intensity increases whereas the Ti-O-Si band nearly disappears. Despite a quite noisy signal, the absorption band around $440 \mathrm{~cm}^{-1}$ seems to split in two lines, at $430 \mathrm{~cm}^{-1}$ (Ti-O stretching) ${ }^{14}$ and $\sim 450 \mathrm{~cm}^{-1}$ (Si-O-Si asymmetric rocking). Moreover, a band is noticed at $266 \mathrm{~cm}^{-1}$ as in the pure $\mathrm{TiO}_{2}$ anatase spectrum. Similar spectra have been obtained for mixed B films, only band intensities are different. These results could be explained by phase segregation, i.e. a partial (or total) separation of the $\mathrm{TiO}_{2}$ and $\mathrm{SiO}_{2}$ phases; $\mathrm{TiO}_{2}$ crystallizes in anatase structure whereas $\mathrm{SiO}_{2}$ remains amorphous. The intensity increase of the band at 1075 $\mathrm{cm}^{-1}$ after annealing can occur because the FTIR spectra have been obtained in transmission configuration where $\mathrm{SiO}_{2}$ signal is provided by both the $\mathrm{TiO}_{2}-\mathrm{SiO}_{2}$ film and $\mathrm{SiO}_{2}$ formed during annealing on the backside of the substrate.

Figure 2 shows the evolution of the Raman spectra of A and B mixed films before and after several thermal annealings at $700^{\circ} \mathrm{C}, 800^{\circ} \mathrm{C}$ and $950^{\circ} \mathrm{C}$ for 1 hour under air. Spectra of pure $\mathrm{SiO}_{2}$ and pure $\mathrm{TiO}_{2}$ films are also shown. It is to be noticed that the pure $\mathrm{SiO}_{2} / \mathrm{Si}$ spectrum is identical to the $\mathrm{Si}$ substrate spectrum (not shown in the figure). The pure $\mathrm{TiO}_{2}$ film spectrum contains three lines at 143,395 and $638 \mathrm{~cm}^{-1}$ which are characteristic of the $\mathrm{TiO}_{2}$ anatase phase and assigned to $\mathrm{E}_{\mathrm{g}}, \mathrm{B}_{\mathrm{lg}}$ and $\mathrm{E}_{\mathrm{g}}$ modes, respectively ${ }^{22}$.

The spectra of as-deposited mixed $\mathrm{TiO}_{2}-\mathrm{SiO}_{2}$ films do not differ from that of the Si substrate nor from the $\mathrm{SiO}_{2} / \mathrm{Si}$ one, which is in agreement with an amorphous state and with the fact that $\mathrm{TiO}_{2}-\mathrm{SiO}_{2}$ composite films are known to stay amorphous as long as the $\mathrm{SiO}_{2}$ atomic content exceeds $15 \%{ }^{23}$. After annealing at $700^{\circ} \mathrm{C}$ a small and broad band can be noticed at $\sim 151 \mathrm{~cm}^{-1}$ for both films; its intensity is slightly stronger in B film. This band is assigned to the low wavenumber anatase $\mathrm{E}_{\mathrm{g}}$ mode and is a sign of the beginning of $\mathrm{TiO}_{2}$ crystallization ${ }^{24}$. When the annealing temperature is raised to $800^{\circ} \mathrm{C}$, the $\mathrm{E}_{\mathrm{g}}$ line gets better defined and shifts slowly to smaller wavenumbers. After annealing at $950^{\circ} \mathrm{C}$, the spectra of both films show a well-defined $\mathrm{E}_{\mathrm{g}}$ line at $\sim 143 \mathrm{~cm}^{-1}$ in B film and $\sim 146 \mathrm{~cm}^{-1}$ in A film, as well as two other lines characteristic of the $\mathrm{TiO}_{2}$ anatase phase. Whatever the annealing temperature, the Raman lines of the $\mathrm{TiO}_{2}$ anatase phase in films with higher $\mathrm{TiO}_{2}$ content are always sharper and slightly shifted towards lower wavenumbers in comparison with those with lower $\mathrm{TiO}_{2}$ content.

Let us now discuss the two possible origins of the shift of the $\mathrm{TiO}_{2} \mathrm{E}_{\mathrm{g}}$ mode from 151 to $143 / 146 \mathrm{~cm}^{-1}$ induced by the thermal treatment: a size effect or a stress effect. The increase of the annealing temperature improves the crystalline state of $\mathrm{TiO}_{2}$ and usually causes an increase of the 
$\mathrm{TiO}_{2}$ grain size. The Raman spectrum of $\mathrm{TiO}_{2}$ nanoparticles has been extensively studied due to the unusual broadening and shifts of the Raman lines with decreasing particle size and because the intense $\mathrm{E}_{\mathrm{g}}$ line appears as the most sensitive line to reveal size effects. The shift towards low wavenumbers actually indicates an increase in particle size, as reported in several papers ${ }^{25,26}$. The second possible origin of such a shift could be a compressive stress effect of the $\mathrm{SiO}_{2}$ matrix on the $\mathrm{TiO}_{2}$ nanograins. The $\mathrm{TiO}_{2}$ spectra of the films annealed at $950^{\circ} \mathrm{C}$ would thus reveal a stress relaxation of the $\mathrm{TiO}_{2}$ particles, complete in the $\mathrm{B}$ film as observed by the similarity between its Raman spectrum and the reference anatase spectrum, and partial in A. This can be explained by a higher compressive stress of the matrix on the $\mathrm{TiO}_{2}$ crystallites, which are smaller in A film. Indeed, it is reported that an increase in $\mathrm{TiO}_{2}$ content in $\mathrm{TiO}_{2}-\mathrm{SiO}_{2}$ codeposited films involves an increase in $\mathrm{TiO}_{2}$ crystal size ${ }^{6}$. Our Raman results do not allow elimination of one of the two hypotheses since both size and stress effects are related each other; we will see in the following section that TEM observations rather suggest that the stress effect is dominant.

Bright field transmission electron micrographs of mixed A film cross sections and corresponding selected area electron diffraction patterns are reported in Fig. 3. The film thickness indicated on each bright field image was determined with respect to 111 lattice fringes observed on Si substrates (i.e., $d_{111}=3.134 \AA$ ). For the as-deposited sample (Fig. 3a), an amorphous $\mathrm{SiO}_{2}$ layer of about $1.5 \mathrm{~nm}$ in between the thin film and the Si substrate can be identified by its average $Z$ contrast lower than that of the amorphous Ti-Si-O film. Let us note that the film exhibits a speckled contrast which, along with being an effect of the transfer function of the microscope, could partly result from an unmixing of amorphous states. The corresponding electron diffraction pattern (Fig. 3b) is composed of the reflections of the Si substrate oriented along a [110] zone axis and of a broad diffuse ring centered at about $1.8 \AA^{-1}$. After annealing at $950^{\circ} \mathrm{C}$ under air for 1 hour, crystalline particles of anatase $\mathrm{TiO}_{2}$ of less than $10 \mathrm{~nm}$ size and embedded in $\mathrm{SiO}_{2}$ matrix are observed (Figs. 3c and 3d). The anatase structure is unambiguously identified from a comparison between the diffracting rings observed on the corresponding electron diffraction pattern (Fig. 3d) and a simulation of the anatase diagram. Curiously, the $\mathrm{TiO}_{2}$ particles appear to be arranged in a multilayered structure parallel to the (001) surface of the silicon substrate. Six strata of $\mathrm{TiO}_{2}$ particles can be observed in this case. Because of the annealing treatment under air, an important oxidation of the $\mathrm{Si}$ substrate has occurred giving rise to an increase of the $\mathrm{SiO}_{2}$ interface layer thickness (up to $45 \mathrm{~nm}$ ), probably by ionic oxygen and electronic diffusion. This thick $\mathrm{SiO}_{2}$ layer can explain the intensity increase of the $\mathrm{Si}-\mathrm{O}-\mathrm{Si}$ band at $\sim 1075 \mathrm{~cm}^{-1}$ observed in the corresponding FTIR spectrum (Fig. 1d). 
Such an oxidation effect can be avoided by using argon instead of air during the annealing treatment (Fig. 3e). In this case, however, smaller crystalline $\mathrm{TiO}_{2}$ particles of less than $5 \mathrm{~nm}$ size are formed. A multilayered microstructure is also observed but with more strata of $\mathrm{TiO}_{2}$ particles (11 or 12 strata). The identification of the anatase structure shown in Fig. $3 \mathrm{f}$ corresponds to a selected area of a plane view of the thin film. After a second annealing at $950^{\circ} \mathrm{C}$ for 11 hours, only a few changes are observed (Figs. $3 \mathrm{~g}$ and $3 \mathrm{~h}$ ); the average size of $\mathrm{TiO}_{2}$ has slightly increased of about $15 \%$ and, as observed in the thicker part of the cross section, the number of strata of $\mathrm{TiO}_{2}$ particles has reduced to six.

The formation of these alternated $\mathrm{TiO}_{2}-\mathrm{SiO}_{2}$ multilayers or strata in Ti-Si-O thin films after annealing can result from the regular Ti diffusion in the mixed films in order to obtain stress relaxation, as observed in Raman spectra. The number of $\mathrm{TiO}_{2}$ strata varies between six and twelve, depending on the initial film thickness, on the grain size and the gas atmosphere during annealing.

All these results related to mixed $\mathrm{TiO}_{2}-\mathrm{SiO}_{2}$ thin films prepared by aerosol CVD agree with those reported in literature for films obtained by other deposition techniques. Song et $\mathrm{al}^{11}$ prepared $\mathrm{TiO}_{2}-\mathrm{SiO}_{2}$ films by sol-gel from starting solution with $\mathrm{Si} / \mathrm{Ti}$ ratio equal to $1 / 1$. After thermal treatment at temperatures up to $950^{\circ} \mathrm{C}$, they observed anatase $\mathrm{TiO}_{2}$ nanocrystallites embedded in $\mathrm{SiO}_{2}$-rich matrix. Our Raman results show that the incorporation of $\mathrm{SiO}_{2}$ in a $\mathrm{TiO}_{2}$ film raises the crystallization temperature of the $\mathrm{TiO}_{2}$ anatase phase as reported by Giauque et al ${ }^{7}$ et by Sankur et $\mathrm{al}^{6}$ on mixed $\mathrm{TiO}_{2}-\mathrm{SiO}_{2}$ films prepared by reactive magnetron sputtering and electron beam evaporation, respectively.

\section{CONCLUSIONS}

Complementary techniques were used to study the influence of thermal annealing on the structure and microstructure of $100 \mathrm{~nm}$ thick $\mathrm{TiO}_{2}-\mathrm{SiO}_{2}$ films deposited by aerosol CVD at atmospheric pressure.

Although the films remain X-ray amorphous at annealing temperatures as high as $950^{\circ} \mathrm{C}$, FTIR and Raman spectroscopy indicate that $\mathrm{TiO}_{2}$ crystallizes in anatase structure from temperature at around $700^{\circ} \mathrm{C}$. More details about the phase segregation and film microstructure are given by TEM analysis. Especially, anatase $\mathrm{TiO}_{2}$ nanograins embedded in a $\mathrm{SiO}_{2}$ matrix are observed as an alternated $\mathrm{SiO}_{2} / \mathrm{TiO}_{2}$ multilayered structure. The particle size and the number of layers are strongly dependent upon air or argon atmosphere during thermal annealing: about 5 
and $10 \mathrm{~nm}$ size, and 6 and 12 layers, respectively, for films annealed at $950^{\circ} \mathrm{C}$ for 1 hour. In agreement with Raman results, such a multilayered structure may favour a stress relaxation in the films. All these results indicate that $\mathrm{TiO}_{2}-\mathrm{SiO}_{2}$ films belong to the quasi binary Mictamict alloys (mictamict: mictos-amictos in Greek, means miscible-immiscible) ${ }^{7}$.

\section{ACKNOWLEDGMENTS}

This work was supported by the European Community in the framework of the Network of Excellence FAME (Functional Advanced Materials and Engineering of hybrids and ceramics). We thank also Dr. Jens Kreisel (LMGP, Grenoble, France) for his helpful remarks. 


\section{References}

1. M.F. Ouellette, R.V. Lang, K.L. Yan, R.W. Bertram, R.S. Owles: "Experimental studies of inhomogeneous coatings for optical applications”, J. Vac. Sci. Technol. A 9, 1188 (1991).

2. Y. Sorek, R. Reisfeld, I. Finkelstein, S. Ruschin: "Sol-gel glass waveguides prepared at low temperature", Appl. Phys. Lett. 63, 3256 (1993).

3. X. Orignac, D. Barbier, X.M. Du, R.M. Almeida: "Fabrication and characterization of sol-gel planar waveguides doped with rare-earth ions", Appl. Phys. Lett. 69, 895 (1996).

4. B.D. Fabes, D.P. Birnie, B.J.J. Zelinski: "Porosity and composition effects in sol-gel derived interference filters", Thin Solid Films 254, 175 (1995).

5. D. Brassard, D. K. Sarkar, M. A. El Khakani, L. Ouellete: "High-k titanium silicate thin films grown by reactive magnetron sputtering for complementary metal-oxide-semiconductor applications”, J. Vac. Sci. Technol. A 22, 851 (2004).

6. H. Sankur, W. Gunning: "Crystallisation and diffusion in composite $\mathrm{TiO}_{2}-\mathrm{SiO}_{2}$ thin film", $J$. Appl. Phys. 66, 4747 (1989).

7. P.H. Giauque, H.B. Cherry, M.A. Nicolet: "Thermal stability of amorphous thin films: $\mathrm{Ti}_{3} \mathrm{Si}_{1} \mathrm{O}_{8}$ vs. $\mathrm{TiO}_{2}$ and mictamict compounds", Thin Solid Films 394, 136 (2001).

8. D. K. Sarkar, E. Desbiens, M.A. El Khakani: "High-k titanium silicate dielectric thin films grown by pulsed laser deposition", Appl. Phys. Lett. 80, 294 (2002).

9. Z. Jiwei, Y. Xi, Z. Liangying: "Characterization and optical propagation loss of sol-gel derived $\mathrm{TiO}_{2} / \mathrm{SiO}_{2}$ films", J. Phys. D: Appl. Phys. 33, 3013 (2000).

10. M. Langlet, in Handbook of Sol-Gel Science and Technology: Processing Characterization and Applications, edited by S. Sakka, Sol-Gel Processing, Vol. 1, (Kluwer Academic Publishers, Norwell, MA, Dordrecht, The Netherlands, 2005), p 331.

11. C.F. Song, M.K. Lü, P. Yang, D. Xu, D.R. Yuan: "Structure and photoluminescence properties of sol-gel $\mathrm{TiO}_{2}-\mathrm{SiO}_{2}$ films", Thin Solid Films 413, 155 (2002).

12. R.C. Smith, N. Hoilien, C. Dykstra, S.A. Campbell, J.T. Roberts, W.L. Gladfelter: "CVD of $\mathrm{Ti}_{\mathrm{x}} \mathrm{Si}_{1-\mathrm{x}} \mathrm{O}_{2}$ Films: Precursor Chemistry Impacts Film Composition”, Chem. Vap. Deposition 9, 79 (2003).

13. S.M. Lee, J.H. Park, K.S. Hong, W.J. Cho, D.L. Kim: "The deposition behaviour of $\mathrm{SiO}_{2}$ $\mathrm{TiO}_{2}$ thin film by metalorganic chemical vapour deposition method", J. Vac. Sci. Technol. A 18, 2384 (2000). 
14. Q. Fang, M. Meier, J.J. Yu, Z.M. Wang, J.-Y. Zhang, J.X. Wu, A. Kenyon, P. Hoffmann, I.W. Boyd: "FTIR and XPS investigation of Er-doped $\mathrm{SiO}_{2}-\mathrm{TiO}_{2}$ films", Mater. Sci. Eng. B 105, 209 (2003).

15. S. Larouche, H. Szymanowski, J.E. Klemberg-Sapieha, L. Martinu, S.C. Gujrathi: "Microstructure of plasma-deposited $\mathrm{SiO}_{2} / \mathrm{TiO}_{2}$ optical films", J. Vac. Sci. Technol. A 22, 1200 (2004).

16. A. Hodroj, J.L. Deschanvres, U. Gottlieb: "Growth of amorphous Ti-Si-O thin films by aerosol chemical vapor deposition process at atmospheric pressure", J. Electrochem. Soc. 155, D110 (2008).

17. M. Machida, K. Norimoto, T. Watanabe, K. Hashimoto, A. Fujishima: "The effect of $\mathrm{SiO}_{2}$ addition in super-hydrophilic property of $\mathrm{TiO}_{2}$ photocatalyst”, J. Mater. Sci. 34, 2569 (1999).

18. M.F. Best, R.A. Condrate: "A Raman study of $\mathrm{TiO}_{2}-\mathrm{SiO}_{2}$ glasses prepared by sol-gel processes", J. Mater. Sci. Lett. 4, 994 (1985).

19. M. Labeau, P. Rey, J.L. Deschanvres, J.C. Joubert, G. Delabouglise: "Thin films of highresistivity zinc oxide produced by a modified CVD method", Thin Solid Films 213, 94 (1992).

20. A. Hodroj, H. Roussel, A. Crisci, F. Robaut, U. Gottlieb, J.L. Deschanvres: "Density, thickness and composition measurements of $\mathrm{TiO}_{2}-\mathrm{SiO}_{2}$ thin film by coupling X-ray reflectometry, ellipsometry and electron probe microanalysis”, Appl. Surf. Sci. 253, 363 (2006).

21. R.J. Gonzalez, R. Zallen, H. Berger: "Infrared reflectivity and lattice fundamentals in anatase $\mathrm{TiO}_{2}$, Phys. Rev. B 55, 7014 (1997).

22. G. Busca, G. Ramis, J.M.G. Amores, V.S. Escribano, P. Piaggio: "FT Raman and FTIR studies of titania and metatitanate powders", J. Chem. Soc., Faraday Trans. 90, 3181 (1994).

23. D.M. Sanders, E.N. Farabaugh, W.K. Haller: "Glassy optical coatings by multisource evaporation", Proc. SPIE-Int. Soc. Opt. Eng. 346, 31 (1982).

24. H. Chang, P.J. Huang: "Thermo-Raman Studies on Anatase and Rutile”, J. Raman Spectrosc. 29, 97 (1998).

25. H.C. Choi, Y.M. Jung, S.B. Kim: "Size effects in the Raman spectra of $\mathrm{TiO}_{2}$ nanoparticles", Vib. Spectrosc. 37, 33 (2005).

26. S. Kelly, F.H. Pollak, M. Tomkiewicz: "Raman Spectroscopy as a Morphological Probe for $\mathrm{TiO}_{2}$ Aerogels", J. Phys. Chem. B 101, 2730 (1997). 


\section{Figure captions}

Fig. 1: Typical FTIR spectra of (a) amorphous $\mathrm{SiO}_{2}$ film, (b) anatase $\mathrm{TiO}_{2}$ film, a mixed $\mathrm{TiO}_{2}-$ $\mathrm{SiO}_{2}$ film (A: atomic ratio $\mathrm{TiO}_{2} / \mathrm{SiO}_{2}=40 / 60$ ), (c) as-deposited and (d) annealed for 1 hour at $950^{\circ} \mathrm{C}$ under air.

Fig. 2: Raman spectra of amorphous $\mathrm{SiO}_{2}$ film, anatase $\mathrm{TiO}_{2}$ film, mixed $\mathrm{TiO}_{2}-\mathrm{SiO}_{2}$ films with atomic ratios $\mathrm{TiO}_{2} / \mathrm{SiO}_{2}=40 / 60(\mathrm{~A})$ and $56 / 44(\mathrm{~B})$ as-deposited and annealed at $700^{\circ} \mathrm{C}, 800^{\circ} \mathrm{C}$ and $950^{\circ} \mathrm{C}$ for 1 hour under air.

Fig. 3: Bright field transmission electron micrographs and selected area diffraction patterns of a mixed $\mathrm{TiO}_{2}-\mathrm{SiO}_{2}$ film (A: atomic ratio $\left.\mathrm{TiO}_{2} / \mathrm{SiO}_{2}=40 / 60\right)(\mathrm{a}, \mathrm{b})$ as-deposited, (c, d) annealed for 1 hour at $950^{\circ} \mathrm{C}$ under air, (e, f) annealed for 1 hour at $950^{\circ} \mathrm{C}$ under argon, (g) annealed for 12 hours at $950^{\circ} \mathrm{C}$ under argon. The insets in (a), (c) and (e) correspond to high resolution images of the $\mathrm{Si} /$ film interface. A multilayer microstructuring is shown in (h). 


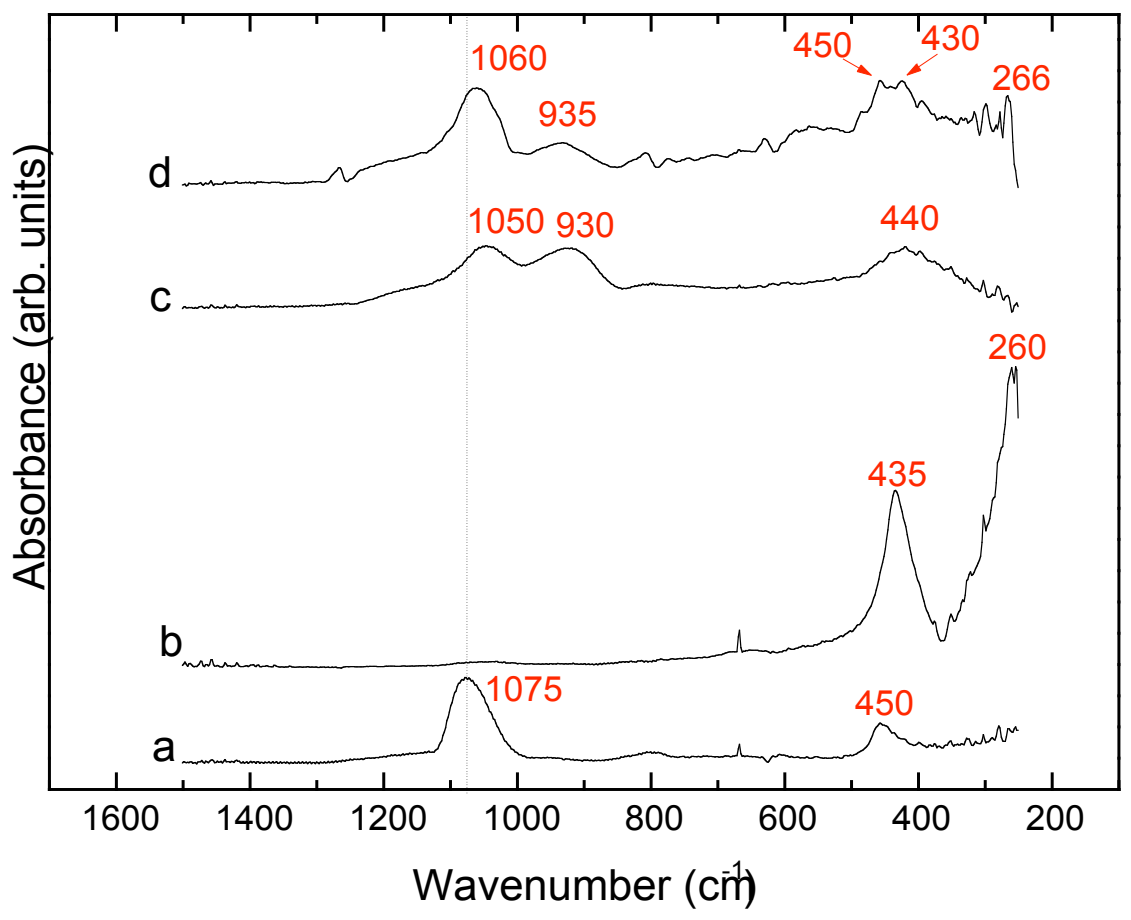

Fig. 1 


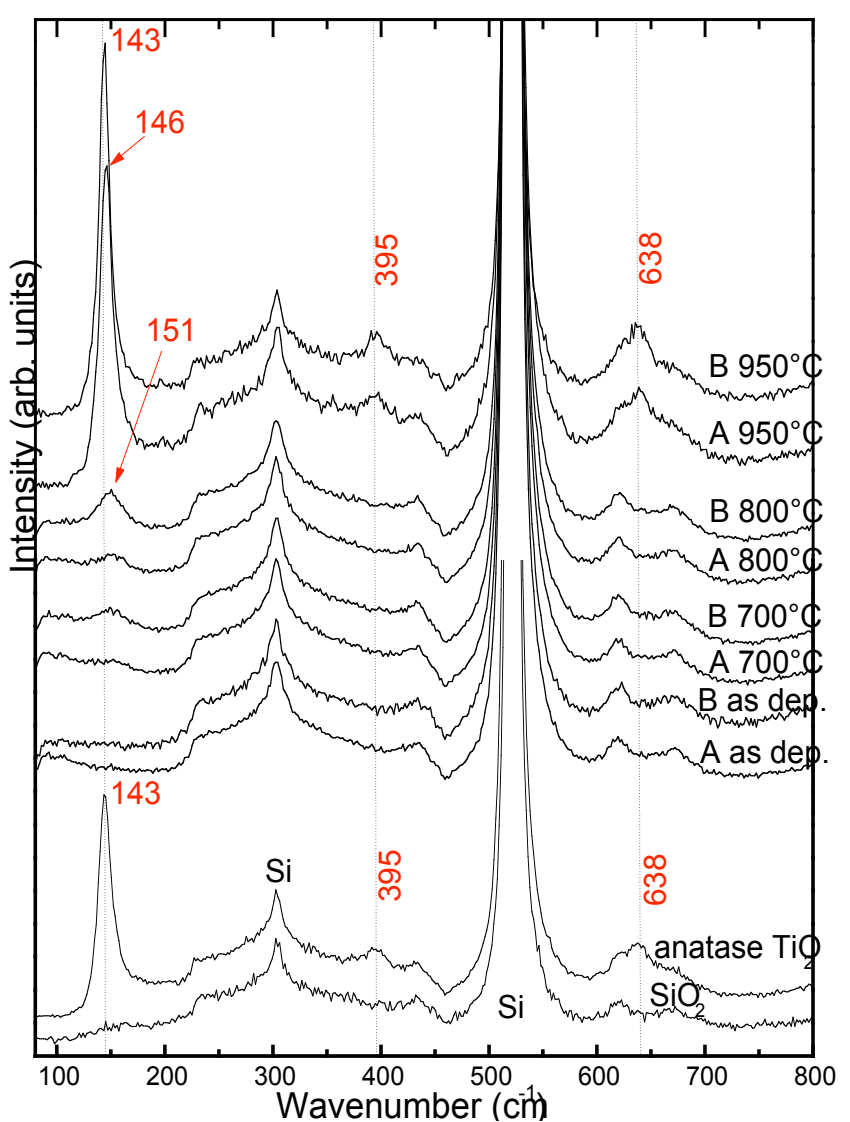

Fig. 2 


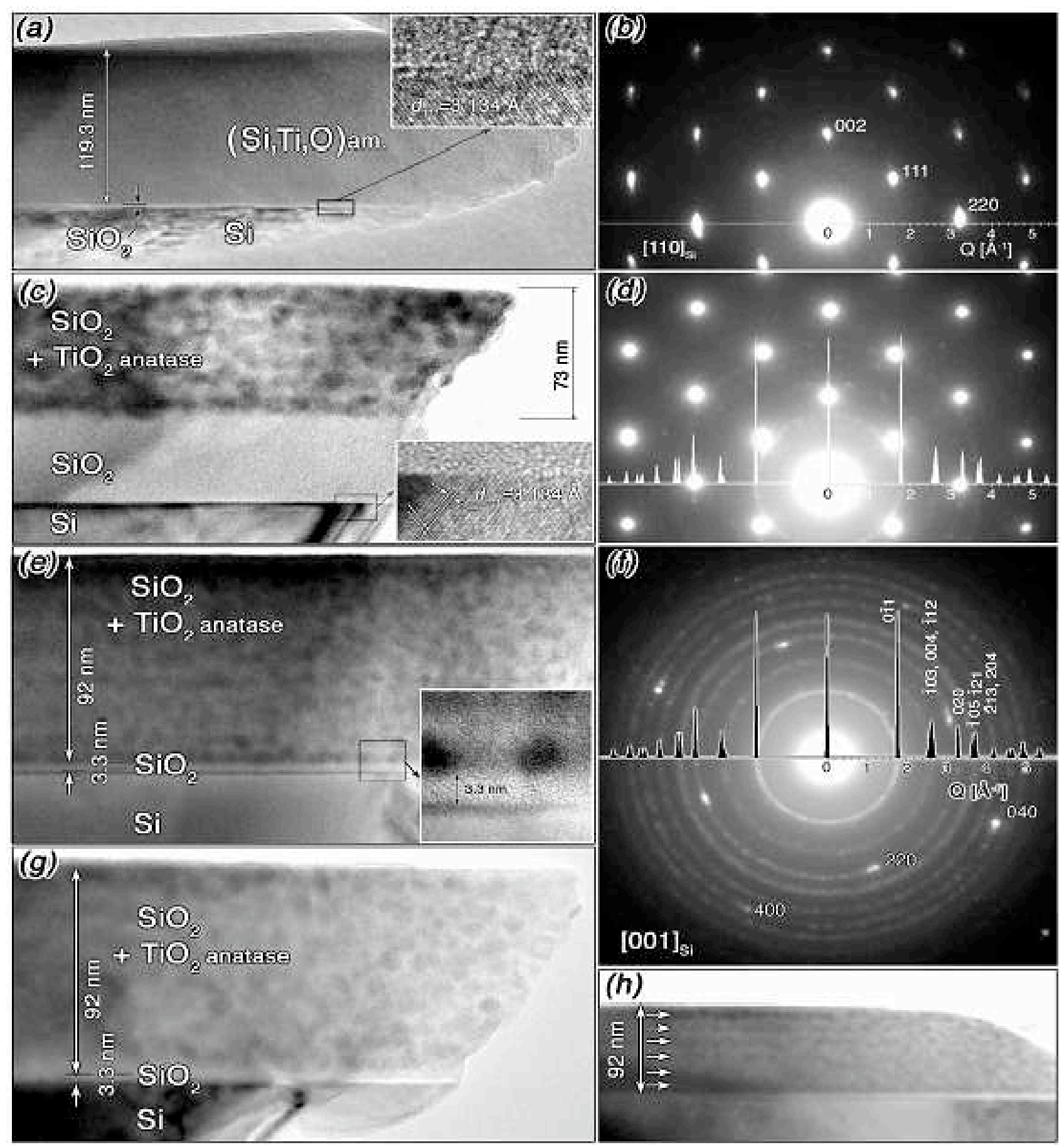

Fig. 3 